\title{
Fungicidas protetores e sistêmicos no controle de Corynespora cassiicola em soja
}

\author{
Matheus Bravo de Souza ${ }^{1}$, Roberta Luiza Vidal ${ }^{1}$ \\ ${ }^{1}$ Universidade Estadual Paulista, Câmpus de Jaboticabal, São Paulo, Brasil. E-mail: matheusbravosouza@gmail.com \\ robertalvidal@gmail.com
}

Recebido: 25/08/2017; Aceito: 04/06/2018

\section{RESUMO}

A mancha alvo da soja vem ganhando notoriedade no Brasil, sendo poucos os estudos que visaram identificar controles químicos eficientes. $\mathrm{O}$ objetivo deste trabalho foi avaliar o efeito de fungicidas protetores, sistêmicos e associação entre ambos no controle desta doença, em casa de vegetação. O experimento foi conduzido em delineamento inteiramente casualizado, com sete repetições, utilizando plantas de soja da cultivar M6410 IPRO. O fungicida Oxicloreto de cobre SC foi previamente aplicado nas plantas no estádio V4 e, os fungicidas Trifloxistrobina + Protioconazol, Azoxistrobina + Ciproconazol e Fluxapiroxade + Piraclostrobina, isolados e em associação, foram aplicados após a inoculação dos conídios. As avaliações foram realizadas semanalmente, baseadas em escala de notas de severidade da doença. Os dados de severidade foram utilizados para o cálculo da área abaixo da curva de progresso da doença (AACPD). Todos os tratamentos foram eficientes em reduzir a severidade da mancha alvo em soja ao final das avaliações. O tratamento Oxicloreto de cobre SC + Azoxistrobina + Ciproconazol foi o que mais suprimiu o desenvolvimento da doença ao longo do experimento, evidenciando que a associação de fungicidas protetores e sistêmicos pode ser utilizada como prática viável para controle desta doença.

Palavras-chave: controle químico, Glycine max, mancha alvo da soja.

\section{Protectives and systemic fungicides in the Corynespora cassiicola control in greenhouse conditions}

\begin{abstract}
The soybean target spot is gaining notoriety in Brazil, with few studies aimed at identifying efficient chemical controls. The objective was to evaluate the effect of protective fungicides, systemic and protective associated with systemic in control of soybean target spot in the greenhouse. The experiment was conducted in a completely randomized design, with seven replications, using soybean plants of the M6410 IPRO variety. The fungicide copper oxychloride, was previously applied to plants in V4 stage and the Trifloxystrobin + Prothioconazole fungicide, Azoxystrobin + Cyproconazole and fluxapyroxad + pyraclostrobin alone and in combination were applied after the inoculation of conidia. The evaluations were performed weekly, based on a scale of disease severity notes. The severity data were used to calculate the area under the disease progress curve (AUDPC). All treatments were efficient in reducing the severity of the soybean target spot at the end of the evaluations. The copper + SC + Azoxystrobin + Ciproconazole treatment was the most suppressing the development of the disease throughout the experiment, showing that the association of protective and systemic fungicides can be used as a viable practice to control this disease.
\end{abstract}

Keywords: Chemical control; Glycine max; Soybean target spot. 


\section{Introdução}

A soja [Glycine $\max$ (L.) Merril.] está entre as culturas de maior importância econômica para o Brasil, sendo o grão mais produzido. Segundo a CONAB (2017) a produção total de grãos no país foi de 186.6 milhões de toneladas na safra 2015/2016, tendo a soja respondido por mais da metade deste valor, com 95.4 milhões de toneladas.

Dentre as doenças foliares que afligem esta cultura, a mancha alvo, causada pelo fungo Corynespora cassiicola, vem ganhando notoriedade. Em consequência do aumento da semeadura de cultivares suscetíveis, sua incidência tem aumentado nas últimas safras, sendo encontrada em praticamente todas as regiões de cultivo do país (Godoy et al., 2012). Godoy et al. (2016) mencionam reduções na produtividade de até $35 \%$ em cultivares susceptíveis, enquanto Silva et al. (2008) relatam perdas frequentes de 10 a $20 \%$ ocasionadas pelo patógeno no estado de Tocantins.

Trata-se de um fungo necrotrófico que destrói as células das folhas para obter nutrientes (Lamotte et al., 2007) e é favorecido por alta umidade e altas temperaturas (Fortunato et al., 2015). Segundo Godoy et al. (2016) os sintomas iniciam-se nas folhas com pontuações pardas de halo amarelado, que evoluem para grandes manchas circulares de coloração acastanhada, sendo que estas normalmente apresentam pontuações no centro e anéis concêntricos de coloração mais escura. $\mathrm{O}$ fungo sobrevive em restos culturais e sementes infectadas, podendo colonizar uma ampla gama de resíduos no solo. Cultivares mais sensíveis a esta doença podem sofrem intensa desfolha e apresentarem também manchas nas hastes e vagens.

As estratégias de manejo recomendadas para controle desta doença são a utilização de cultivares resistentes, o tratamento de sementes, a rotação/sucessão de culturas com milho ou outras espécies de gramíneas e o controle químico com fungicidas (Godoy et al. 2016; Ribeiro et al., 2017).

As primeiras recomendações de fungicidas para cultura no Brasil foram feitas nos anos de 1996 e 1997, para controle de oídio (Erysiphe difusa). Entretanto, foi com a entrada da ferrugem asiática da soja (Phakopsora pachyrhizi Syd. \& P. Syd.) em 2001, que houve uma intensificação na utilização destes produtos. Com a redução na eficiência de triazóis no controle da ferrugem, a partir de 2007 foi recomendado que apenas a mistura de triazóis e estrobirulinas fossem usadas no controle desta (Godoy et al., 2012).

Mesmo com frequentes aplicações de fungicidas na cultura, a mancha alvo ainda é frequentemente constatada em campos de cultivares susceptíveis (Xavier et al., 2013). Sendo que falhas no controle com a utilização de benzimidazóis já foram relatadas (Xavier et al., 2013; Avozani et al., 2014).
Dada a dificuldade no controle de C. cassiicola, o objetivo do presente trabalho foi avaliar a eficiência de fungicidas protetores, sistêmicos e da associação de ambos no controle deste fitopatógeno.

\section{Material e Métodos}

$\mathrm{O}$ experimento foi conduzido em casa de vegetação no município de Jaboticabal - SP, de coordenadas $21^{\circ} 16^{\prime} 29^{\prime \prime} \mathrm{S}$ e $48^{\circ} 20^{\prime} 08^{\prime \prime} \mathrm{W}$, no período de janeiro a março de 2015. Foram utilizadas plantas da cultivar M6410 IPRO, semeadas em vasos plásticos com $2 \mathrm{~kg}$ da mistura de areia e substrato (1:1), deixando-se uma planta por vaso. $\mathrm{O}$ delineamento experimental foi inteiramente casualizado, com sete repetições, onde cada repetição foi constituída por um vaso.

Os conídios de C. cassiicola foram isolados de folhas de soja sintomáticas em meio ágar-água, sendo posteriormente multiplicados em meio de cultura BDA (batata-dextrose-ágar), contido em placas de Petri. Estas foram acondicionadas em câmara de crescimento a 25 ${ }^{\circ} \mathrm{C}$, durante 15 dias, até obtenção de esporulação abundante.

Todas as aplicações de fungicidas foram realizadas utilizando um pulverizador elétrico com pressão de 30 psi, bico de jato plano duplo modelo TJ 60-11004 e calibrado para volume de calda de 100 litros/ha, até que atingisse o ponto de escorrimento. Os tratamentos estão descritos na Tabela 1.

Tabela 1. Tratamentos e doses testadas no experimento para controle da mancha alvo da soja em casa de vegetação. Jaboticabal, SP, 2015.

\begin{tabular}{ll}
\hline Tratamentos & Dose (L/ha) \\
\hline 1. Testemunha & - \\
2. Oxicloreto de cobre SC & 0,5 \\
3. Mancozeb & 1,5 \\
4. Trifloxistobina + Protioconazol & 0,3 \\
5. Oxicloreto de Cobre SC e & $0,5+0,3$ \\
Trifloxistrobina + Proticonazol & 0,5 \\
6. Azoxistrobina + Ciproconazol & \\
7. Oxicloreto de cobre SC e Azoxistrobina & $0,5+0,5$ \\
+ Ciproconazole & 0,3 \\
8. Fluxapiroxade + Piraclostrobina & \\
9. Oxicloreto de cobre SC e Fluxapiroxade & $0,5+0,3$ \\
+ Piraclostrobina & \\
\hline
\end{tabular}

Para avaliar o efeito protetor e curativo, os fungicidas protetores foram aplicados às plantas no estádio V4 (Fehr \& Caviness, 1977) pelo período da manhã. Posteriormente, no período da tarde, realizou-se a inoculação das plantas com uma concentração de $3 \mathrm{x}$ $10^{4}$ conídios $\mathrm{ml}^{-1}$ até o ponto de escorrimento, com auxílio de um aspersor manual. Após a inoculação, as plantas foram tratadas com fungicidas sistêmicos e 
mantidas em câmara úmida por 48 horas a fim de favorecer o processo infeccioso. Visando garantir a presença de água livre na folha, o sistema de nebulização foi acionado durante 15 minutos, em intervalos de 6 horas durante todo o ciclo da cultura.

As avaliações foram realizadas semanalmente, com início no aparecimento dos primeiros sintomas e até a senescência das folhas, perfazendo um total de cinco avaliações. Estas foram baseadas na severidade média da doença em folíolos do terço superior e inferior da planta, utilizando-se escala diagramática de severidade da doença proposta por Soares et al. (2009), atribuindose notas de 1 a 7 , de acordo com a Figura 1.

Os dados de severidade foram utilizados para o cálculo da área abaixo da curva de progresso da doença, baseado no modelo proposto por Campbell \& Madden (1990):

$$
\mathrm{AACPD}=\Sigma\left(\left(\mathrm{X}_{\mathrm{i}}+\mathrm{X}_{\mathrm{i}+1}\right)\left(\mathrm{t}_{\mathrm{i}+1}-\mathrm{t}_{\mathrm{i}}\right)\right) / 2
$$

onde $\mathrm{n}$ corresponde ao número de avaliações de severidade, $X_{i}$ a severidade da doença e $\left(t_{i+1}-t_{i}\right)$ ao número em dias entre as avaliações.

Para o cálculo da porcentagem de controle (PC), foi aplicada a fórmula:

$\mathrm{PC}=$ Doença na Testemunha - Doença no Tratamento $\times 100$ Doença na Testemunha

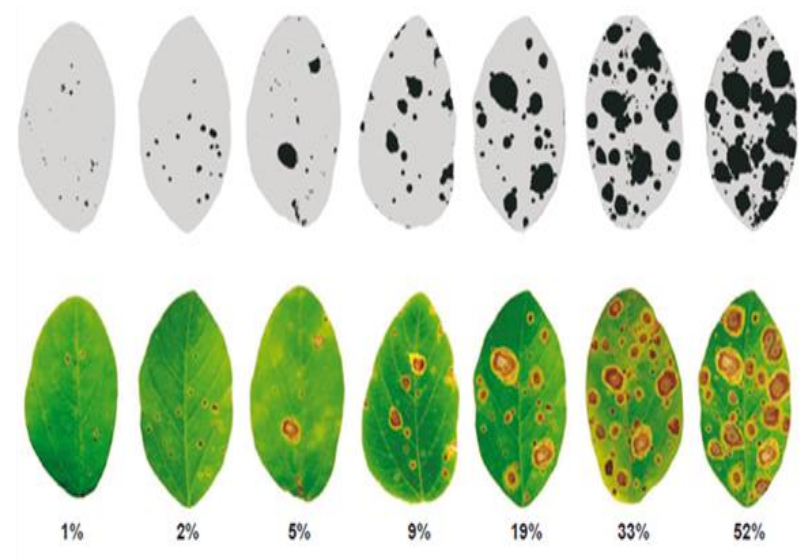

Figura 1. Escala diagramática para avaliação de severidade da Mancha Alvo da soja

Os dados de doença foram submetidos à análise de variância, e as médias comparadas pelo teste de Tukey ao nível de $5 \%$ de probabilidade utilizando-se o programa SASM-Agri (Canteri et al, 2001).

\section{Resultados e Discussão}

Os primeiros sintomas de mancha alvo ocorreram 20 dias após a inoculação de $C$. cassiicola. Os resultados de severidade encontram-se na Tabela 2. Observou-se ao final das avaliações um aumento na severidade da doença para todos os tratamentos, principalmente na testemunha. Na primeira avaliação, apenas os tratamentos Azoxistrobina + Ciproconazol e Oxicloreto de cobre SC + Azoxistrobina + Ciproconazole diferiram dos demais tratamentos, suprimindo a doença, enquanto os demais tratamentos mostraram valores intermediários entre estes e a testemunha. Já na segunda avaliação, apenas a combinação de Azoxistrobina + Ciproconazol com o fungicida protetor Oxicloreto de cobre SC manteve esta diferença dos demais tratamentos. Estes tratamentos voltam a diferir dos demais, juntamente com Oxicloreto de cobre SC, na terceira avaliação.

$\mathrm{Na}$ quarta e quinta avalição, com exceção do Oxicloreto de cobre SC, Trifloxistobina + Protioconazol e Oxicloreto de cobre $\mathrm{SC}+$ Fluxapiroxade + Piraclostrobina, os demais tratamentos diferiram da testemunha, conferindo um controle à doença. No entanto, na última avalição todos os tratamentos envolvendo aplicação de fungicidas diferiram da testemunha, porém, sem diferirem entre si.

Com relação à eficiência de controle, obtiveram-se valores variando de 57,9 \% para aplicação do fungicida sistêmico Fluxapiroxade + Piraclostrobina até 78,8\% para a combinação dos fungicidas Oxicloreto de cobre SC e Azoxistrobina + Ciproconazole (Figura 2). O menor valor para AACDP foi obtido pelo tratamento Oxicloreto de cobre SC e Azoxistrobina + Ciproconazole, indicando que ao longo das avaliações foi o tratamento que mais suprimiu a doença. Misturas de triazóis e estrobirulinas são comumente utilizadas na cultura da soja visando controle de ferrugem asiática, assim, apenas o acréscimo do fungicida protetor conferiria controle mais eficiente sobre a mancha alvo.

A mistura de Azoxistrobina + Ciproconazole vem sendo relatada como de baixa eficiência no controle de mancha alvo da soja, sendo até mesmo usada apenas para controle de ferrugem asiática em experimentos conduzidos para avaliar controle de mancha alvo por Godoy et al. (2012). Nos experimentos destes autores, os melhores resultados foram obtidos pela mistura de Piraclostrobina + Fluxapiroxade, o que também foi verificado no trabalho de Belufi et al. (2015). Tais divergências podem ser explicadas por diferenças na metodologia, visto que tais trabalhos foram conduzidos sob condições de campo, onde possivelmente vários outros fatores também exerceram influência.

Avozani (2014) também cita a baixa fungitoxicidade de ciproconazol para controle da mancha alvo. No entanto, relata não haverem registros da ocorrência de perda de sensibilidade de estrobirulinas para macha alvo no Brasil. Assim, este grupo continua exercendo um papel importante no manejo deste patógeno.

Ribeiro et al. (2016) avaliando fungicidas aplicados isoladamente ou em combinação com fungicidas protetores, também encontraram maiores taxas de controle de mancha alvo em soja com aumento do número de associações do mancozebe (fungicida 
protetor) com os sistêmicos. Os autores deduziram que estes resultados se devem ao fato do fungicida mancozebe apresentar ação multissítio, com efeito protetor e residual. Estes resultados evidenciam que a utilização de fungicidas protetores associados a sistêmicos se faz de grande valia no controle deste fitopatógeno.

Tabela 2. Comparação de médias de porcentagem de severidade de Corynespora cassiicola da soja. Jaboticabal, 2015.

\begin{tabular}{|c|c|c|c|c|c|c|}
\hline \multirow{2}{*}{ Tratamentos } & 0 DAAS ${ }^{1}$ & 7 DAAS $^{1}$ & 14 DAAS $^{1}$ & 21 DAAS $^{1}$ & 28 DAAS $^{1}$ & 35 DAAS $^{1}$ \\
\hline & \multicolumn{3}{|c|}{ Severidade (\%) } & & & \\
\hline Testemunha & $1,00 \mathrm{a}$ & $1,14 \mathrm{ab}$ & $1,29 \mathrm{ab}$ & $2,36 \mathrm{a}$ & $3,43 \mathrm{a}$ & $6,43 \mathrm{a}$ \\
\hline Occ & $0,50 \mathrm{ab}$ & $0,50 \mathrm{bc}$ & $0,50 \mathrm{c}$ & $1,50 \mathrm{ab}$ & $1,57 \mathrm{ab}$ & $1,43 \mathrm{~b}$ \\
\hline Mancozeb & $0,50 \mathrm{ab}$ & $0,64 \mathrm{bc}$ & $0,64 \mathrm{bc}$ & $1,00 \mathrm{~b}$ & $1,07 \mathrm{~b}$ & $1,64 \mathrm{~b}$ \\
\hline Trifloxi + Proti & $0,79 \mathrm{ab}$ & $1,57 \mathrm{a}$ & $1,57 \mathrm{a}$ & $1,60 \mathrm{ab}$ & $2,14 \mathrm{ab}$ & $2,50 \mathrm{~b}$ \\
\hline Occ e Trifloxi + Proti & $0,50 \mathrm{ab}$ & $0,50 \mathrm{bc}$ & $0,57 \mathrm{bc}$ & $0,79 \mathrm{~b}$ & $0,86 \mathrm{~b}$ & $2,21 \mathrm{~b}$ \\
\hline Azoxis + Cipro & $0,29 \mathrm{~b}$ & $0,50 \mathrm{bc}$ & $0,50 \mathrm{c}$ & $0,64 \mathrm{~b}$ & $1,50 \mathrm{~b}$ & $1,79 \mathrm{~b}$ \\
\hline Occ e Azoxis + Cipro & $0,21 \mathrm{~b}$ & $0,36 \mathrm{c}$ & $0,43 \mathrm{c}$ & $0,64 \mathrm{~b}$ & $0,71 \mathrm{~b}$ & $1,36 \mathrm{~b}$ \\
\hline Fluxa + Pira & $0,64 \mathrm{ab}$ & $0,66 \mathrm{bc}$ & $0,86 \mathrm{abc}$ & $0,93 \mathrm{~b}$ & $1,43 \mathrm{~b}$ & $2,71 \mathrm{~b}$ \\
\hline Occ e Fluxa + Pira & $0,57 \mathrm{ab}$ & $0,57 \mathrm{bc}$ & $0,57 \mathrm{bc}$ & $1,43 \mathrm{ab}$ & $1,55 \mathrm{ab}$ & $2,21 \mathrm{~b}$ \\
\hline $\mathrm{CV}(\%)$ & 15.31 & 17.64 & 15.65 & 16.15 & 20.71 & 14,19 \\
\hline
\end{tabular}

Médias seguidas de mesma letra na coluna não diferem estatisticamente entre si pelo teste de Tukey a $5 \%$ de probabilidade; ${ }^{1}$ Dados transformados em $(x+0,5)^{0,5}$ para análises estatísticas. Occ - Oxicloreto de cobre; Trifloxis + Proti - Trifloxistrobina + Protioconazol; Azoxis + Cipro Azoxistrobina + Ciproconazole; Fluxa + Pira - Fluxapiroxade + Piraclostrobina; DAAS - dias após o aparecimento dos sintomas.

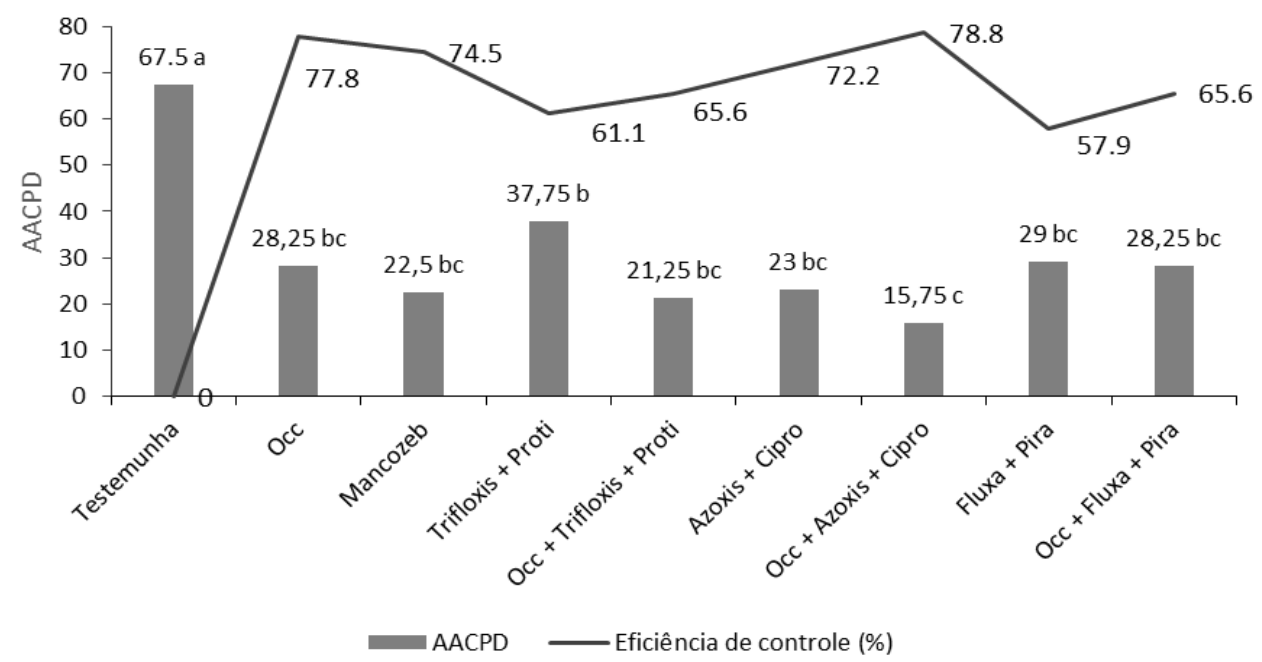

Figura 2. Médias da Área Abaixo da Curva de Progresso da Doença (AACPD) nos diferentes tratamentos. Jaboticabal, SP, 2015. Occ - Oxicloreto de cobre; Trifloxis + Proti - Trifloxistrobina + Protioconazol; Azoxis + Cipro - Azoxistrobina + Ciproconazole; Fluxa + Pira - Fluxapiroxade + Piraclostrobina.

\section{Conclusões}

Os tratamentos com controle químico suprimiram a mancha alvo, sendo que o tratamento Oxicloreto de cobre SC e Azoxistrobina + Ciproconazole apresentou menor AACPD, evidenciando que a aplicação em conjunto de produtos protetores e sistêmicos é ferramenta importante no controle da doença.

\section{Referências Bibliográficas}

Avozani, A., Reis, E.M., Tonin, R.B., 2014. Sensitivity loss by Corynespora cassiicola, isolated from soybean, to the fungicide carbendazim. Summa Phytopathologica, 40, 273276.
Belufi, L.M.R., Pittelkow, F.K., Pasqualli, R.M. Avaliação da eficiência de programas de fungicidas para o controle de doenças na cultura da soja em duas épocas de semeadura no Mato Grosso. Boletim Técnico Safra 2014/15. Fundação de Pesquisa e Desenvolvimento Tecnológico Rio Verde. 2015. 13 p.

Campbell, C.L., Madden, L.V., 1990. Introduction to plant disease epidemiology, first ed. John Wiley \& Sons, New York.

Canteri, M. G., Althaus, R. A., Virgens Filho, J. S., Giglioti, E. A., Godoy, C. V., 2001.

SASM-Agri: sistema para análise e separação de médias em experimentos agrícolas pelos métodos Scott-Knott, Tukey e Duncan. Revista Brasileira de Agrocomputação, 1, 18-24. 
CONAB, 2017. Pesquisa de safras e informações geográficas da agricultura brasileira: Série histórica de área plantada, produtividade e produção - Grãos. http://www.conab.gov.br. (Acessado 18 de julho de 2017).

Fortunato, A.A., Debona, D., Bernardeli, A.M.A., Rodrigues, F.A., 2015. Defence-related enzymes in soybean resistance to target spot. Journal of Phytopathology, 163, 731-742.

Godoy, C. V., Almeida, A. M. R., Costamilan, M. C., Meyer, W. P., Dias, C. D. S., Seixas, R. M., Soares, A. A., Henning, J. T., Yorinori, L. P., Silva, J. F. V., 2016. Doenças da soja, in: Amorim, L., Rezende, J.A.M., Bergamim Filho, A., Camargo, L.E.A. (Org.). Manual de Fitopatologia - Volume 2: Doenças das Plantas Cultivadas. São Paulo: Ceres: São Paulo, pp. 657-676.

Godoy, C. V., Utiamada, C. M., Meyer, M. C., Campo, H. D., Pimenta, C. B., Borges, E.P. Eficiência de fungicidas para o controle de manchaalvo, Corynespora cassiicola, na safra 2011/12: resultados sumarizados dos ensaios cooperativos. Londrina -PR: Embrapa soja, 2012. 6 p. (Circular Técnica 94)

Lamotte, F., Duviau, M.P., Sanier, C., Thai, R., Poncet, J., Bieysse, D., Pujade-Renaud, V., 2007. Purification and characterization of cassiicolin, the toxin produced by Corynespora cassiicola, causal agent of the leaf fall disease of rubber tree. Journal of Chromatography B, 849, 357-362.
Ribeiro, F. C., Colombo, G. A., Carvalho, E. V., Pelúzio, J. M., Erasmo, E. A.L., 2017. Controle químico da mancha-alvo da soja (Corynespora casiicola) no cerrado tocantinenseBrasil. Journal of Bioenergy and Food Science, 4, 26-36.

Ribeiro, F. C., Erasmo, E. A. L., Rocha, F. S., Moraes, E. B., Matos, E. P., 2016. Associação de fungicida protetor com fungicidas sistêmicos no controle de mancha-alvo na cultura da soja. Revista verde de agroecologia e desenvolvimento sustentável, 11, 51-56.

Silva, L.H.C.P., Campos, H. D., Silva, J. C., 2009. Fortalecida e agressiva. Revista Cultivar Grandes Culturas, 114, 20-22.

Soares, R.M., Godoy, C.V., Oliveira, M.C.N. 2009. Escala diagramática para avaliação da severidade da mancha alvo da soja. Tropical Plant Pathology, 34, 333-338.

Xavier, S. A., Canteri, M. G., Barros, D. C. M., Godoy, C. V., 2013. Sensitivity of Corynespora cassiicola from soybean to carbendazim and prothioconazole. Tropical plant pathology, $38,431-435$.

Fehr, W. R., Caviness, C. E. Stages of soybean development. Ames - Iowa: Iowa State University, 1977. 12p. (Special Report 80). 